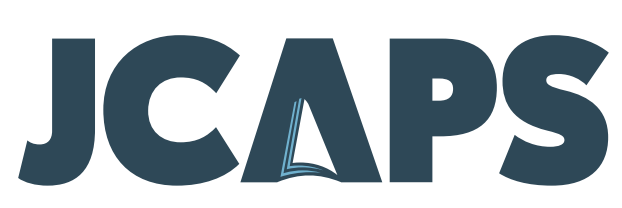

\title{
STUDENT BELONGING: A CRITICAL PILLAR IN THE SCHOLARSHIP OF DIVERSITY, EQUITY, AND INCLUSION IN CAMPUS ACTIVITIES
}

\author{
Adam Peck, Illinois State University \\ David M. Rosch, University of Illinois at Urbana-Champaign \\ Danielle M. De Sawal, Indiana University-Bloomington
}

The scholarship and professional practice of campus activities are likely entering an inflection point in its history. Numerous scholars, pundits, and bloggers have recently described what has become known as the "twin pandemics" - the global spread of Covid-19 and its resulting upheaval, public health crises, and community anxiety, combined with a global-scale reckoning of societal injustice and inequity based on social identity and economic privilege. Indeed, both have served to reinforce and lend focus on the other. Public health crises, for example, lay bare who has resources to address them and who does not. The potential connection to campus activities practice and scholarship was seeded prior to these profoundly disruptive events. Still, both have directly contributed to the speed and strength of discussion in our field for how, why, and for whom we do our work.

The Editorial Board of the Journal of Campus Activities Practice and Scholarship believe that inclusion has always been the central purpose of our work in campus activities and will make a case that this must be our focus as we contemplate how to move forward in a way that has been informed by the "twin pandemics." Diversity, Equity, and Inclusion (DEI), which we will often refer to collectively here, are not simply a current popular fad that will pass as the Covid-19 crisis lessens and attention in higher education passes to other topics. Indeed, the National Association of Campus Activities had begun integrating diversity, equity, and inclusion topics throughout its Association-wide Research Agenda long before most people knew what a "coronavirus" was. But it is also safe to say that our field has evolved in its understanding of how to approach this work. In the previous issue of this Journal, the Editorial Board described the updated Research Agenda, outlining its essential parts and highlighting what had been added from the previous version. Here, we focus on a specific, actionable area within the new Research Agenda - a concept that has served as a longstanding pillar in campus activities work, and also one that could be expanded in our focus on diversity, equity, and inclusion - student sense of belonging.

In that spirit, we are pleased to announce that this Journal will soon produce our first-ever "Special Issue" in 2022. Each article will be designed to contribute to our understanding of the work of campus activities in the context of diversity, equity, and inclusion topics in higher education. We are also proud to be collaborating with a special Guest Editor to provide partnership for leading within this issue, Dr. Mamta Accapadi, the Vice Provost for Student Life at the University of Pennsylvania.

As we set the stage for this important publication, the Editorial Board would like to open a conversation about approaching this critical conversation - not just in our research but also in our practice. This article will make a case that "infusing" EDI into our work isn’t enough; it must become our work. 


\section{DEFINING INVOLVEMENT, ENGAGEMENT, AND LEADERSHIP}

To understand how fundamental supporting DEI progress is to the work of campus activities professionals, we must first focus on defining terms that are often used incorrectly in student affairs publications: involvement, engagement, and leadership. Three primary theories are central to their canon. Astin's Involvement Theory (1984) is perhaps the most familiar to campus activities professionals because it offers validation of the educational benefits of typical campus activities involvement. However, this theory is often misunderstood. While there may be a tendency to view Astin's theory supporting attendance at a co-curricular experience, Astin defined it more concretely as "the amount of physical and psychological energy that the student devotes to the academic experience" (p. 518). Such energy could be expended inside or outside of the formal academic classroom. To us, the noteworthy distinction rests with the level of analysis. Administrators might think in terms of "Over 100 students were involved in the program" when Astin might more insightfully ask, "How much physical or psychic energy did individual students expand as part of their involvement in the program?" The former can summarize involvement across a group, while the latter can only be analyzed individually. The contrast between how the theory is often described and how it was initially written illustrates a fallacy observed in many other contexts- the idea that students can be passive beneficiaries of initiatives organized for them. The focus on the individual student experience is a fundamental key in understanding the concept of student involvement, especially in increasing the degree of diversity, equity, and inclusion that exists in campus activities contexts.

Engagement is another common term relating to campus activities work that similarly is partly misunderstood. Kuh and his colleagues (2007), in their seminal writing on the concept, defined engagement as "participation in educationally effective practices, both inside and outside the classroom, which leads to a range of measurable outcomes" (B12). Whitt, et al. (2005) point out the challenges of seeing the benefits of involvement simply in terms of exposure to opportunities, writing:

"Many colleges claim to provide high-quality learning environments for their students. As evidence, schools point to educationally enriching opportunities they make available, such as honors programs, co-curricular leadership development programs, and collaboration with faculty members on a research topic. Too often, however, such experiences are products of serendipity or efforts on the part of students themselves. Moreover, for every student who has such an experience, there are others who do not connect in meaningful ways with their teachers, their peers, or take advantage of learning opportunities. As a result, many students leave school prematurely, or put so little effort into their learning that they fall short of benefiting from college to the extent they should" (p. 9 and 10)."

Another definition of engagement put forth by $\mathrm{Hu}$ and Kuh (2001) defines engagement as "the quality of effort students themselves devote to educationally purposeful activities that contribute directly to desired outcomes" (p. 555). Again, it is not the experiences themselves that produce desired outcomes, but rather the combination of the quality of that experience and the investment students make in it. It is unclear if campus activities professionals have made that shift in perception within their scholarship. Consider, for example, the educationally purposeful experiences to which Kuh (2008) and his colleagues refer to as "High-Impact Practices" (p. 1 ). When asked what practices are considered high impact, many postsecondary institutions list the prevalence of experiences such as "first-year seminars, learning communities, service-learning or internships" (Kuh, 2008, p. 9-11) on their campuses. However, Peck and Callahan (2019) observed,

"When many think of high impact experiences, they tend to think of a variety of programs which have been demonstrated to produce the "impact" that can come from high-impact programs. What is often undervalued are the conditions that must be present for these programs to be effective. Without the(se) conditions...these experiences are no more high impact than any number of other experiences" (p. 18).

Put another way, we still haven't shifted from focusing on what programs offer to students and what they deliver for the representative body of students in terms of the impact that results. We call on campus activities professionals to begin to make this shift from thinking about involvement and engagement as something that can be assessed 
in counting the number of students that attend programs that occur to measuring how the programs contributed to desired outcomes in the students that attend. Given this shift, it becomes easier to think about the concept of student belonging in a DEI context.

Lastly, leadership is often seen as a valuable and desirable outcome related to helping students become involved and engaged in campus activities initiatives. Many campuses provide leadership development programs and a myriad of opportunities to help students build the capacity to lead their peers, both while on campus and in the professional world upon their graduation. And yet, there continues to be a disconnect between what students might learn in academic leadership programs and how students are prepared for leadership roles on campus and afterward. As Komives, Lucas, and McMahon (2007) explain, “...many students have trouble relating to the leadership literature, much of which is written for corporate chief executive officers (CEOs). Some students find the leaders-focused approaches to be self-centered, and some say, "I'm not a leader. I just want to make a difference." We might respond that the desire to make a difference is not just fundamental for building leadership capacity - it is also a critical part of feeling a sense of belonging.

Another pitfall that co-curricular leadership development faces is that it may sometimes confirm the very stereotypes that it ought to dispel. One such misconception is that leadership can be reduced to a set of individual skills, attributes, or even traits. Komives, Lucas, and McMahon's (2007) well-known definition of leadership as “...a relational and ethical process of people together attempting to accomplish positive change" (p. ix) implicitly challenges the notion of leadership as a set of traits or attributes, or even related to occupying an organizational position. Pfeffer (2015) also challenges the notion that not only does leadership training often focus too much on leadership traits, but focuses on the wrong traits as well, writing, "...the qualities we actually select for and reward in most workplaces are precisely the ones that are unlikely to produce leaders who are good for employees or, for that matter, for long-term organizational performance" (p. 7). Instead, we should view our work as professionals as helping our diverse body of students see themselves as worthy of and possessing the capacity to help "make a difference" - and then supporting them in building the skills to do so. We suggest this might be more difficult than it might seem. Helping a young woman develop the skills to lead her 100-year-old social sorority after her slightly older peers recruited her to the role requires different work than helping a first-generation, underrepresented student organize a rally to focus attention on financial aid reform. We believe both are aspects of campus activities "leadership development work." An intentional focus on cultivating belonging through student leadership could do much to close this gap. When groups feel included and valued, they tend to develop the kind of cohesion that allows them to thrive. How student leadership programs might look different if they were focused on belonging deserves considerable attention within the campus activities profession.

\section{STUDENT BELONGING - EVOLVING IN PURPOSE}

The scholarship and context for campus activities work have significantly evolved since the early work of Astin and other researchers focused on student engagement and belonging, particularly regarding the role of diversity. Consider our profession's Council for the Advancement of Standards in Higher Education (CAS; 2019), which first produced a Self-Assessment Guide for Student Activities units in 1988. Early versions of the CAS standards articulate the mission of campus activities to, "...complement the institution's academic programs. The purposes must enhance the overall educational experience of students through development of, exposure to, and participation in social, cultural, multicultural, intellectual, recreational, community service, and campus governance programs" (CAS, 2003, p. 52). In this frame, "diversity" is implied through "multicultural" programs, and is positioned as something that a student might be exposed to through involvement in an experience. A campus activities professional with a commitment to diversity was encouraged to ensure that programs appealed to a broad audience. Later versions of CAS (2003) Standards included statements like, "Programs should be comprehensive and should reflect and promote the diversity of student interests and needs" (p. 52). Still missing is guidance regarding the intended outcomes for programs and the campus activities professional's obligation in ensuring them.

The most recent 10th edition of the CAS (2019) standards reveals how significantly the purpose of campus activities programs has evolved. This version reads, "The mission of Campus Activities Programs must be to enhance 
the overall student educational experience through providing activities and events to facilitate students' sense of belonging and connection to the institution and the overall academic mission" (p.72). This mission calls our field to build belonging and connection for and among ALL students (first-generation, international, those with physical or mental disabilities, online, working adult, etc.), not just those that have traditionally been well-served.

"DEI" has in some ways already become a cognitive and verbal shorthand for a variety of values, issues, initiatives, and goals in higher education. Dangerously, as some have observed, the terms and its respective three letters are often employed as if they represent one amorphous concept rather than meaningfully differentiating the terms (Johnson and Pierre, 2021). Each term, however, has a distinct and significant meaning to campus activities professionals. "Diversity" refers to recognizing that our campuses reflect many different backgrounds, experiences, identities, and expressions. "Equity" refers to our responsibility to ensure that all students share equal access to institutional resources ensuring their needs are equally met. "Inclusion" obligation that all students, regardless of background and individual attributes, feel valued by their respective institutions and effectively connected to and within them.

When we consider how diversity, equity, and inclusion ought to be reflected in the work of campus activities professionals, at the most superficial level, we can see that diversity compels us to provide activities, events, and leadership experiences that reflect the wide variety of student wants, needs, and perspectives. Equity focuses campus activities professionals on ensuring that their events are accessible and educationally developmental for all. Inclusion is the concept that likely resonates the most in the history of campus activities work, given that helping others connect and engage has long been a central role in our mission as campus activities professionals. Inclusion is likewise central to the role of DEI work as well. As Johnson and Pierre (2021) point out, "Inclusion is the cornerstone of DEI work because one can neither celebrate diversity or experience equity without it" (p. 61).

While involvement, engagement, and leadership remain essential goals, when viewed through an inclusion lens, campus activities professionals may run the risk of treating a student's involvement (or lack of it), their engagement (or lack of it), and leadership development (or lack of it) as ultimately the result of decisions that the student themselves makes - rather than a reaction to the conditions on campus that either send signals of inclusion or exclusion. Johnson and Pierre (2021) explain, "For many years, student affairs literature has touted the importance of "involvement" and "engagement" in promoting student learning and success. An essential but historically underappreciated precursor is "inclusion." How can one be involved or engaged unless they are first included?" (p. 61).

Perhaps even more fundamentally, the concepts of diversity, equity, and inclusion are founded upon the concept of student sense of belonging. If we were to imagine a Venn diagram or mental map of the terms involvement, engagement, leadership, equity, diversity, and inclusion, a case could be made that belonging is where all of these concepts intercept. How can it matter if a student attends an event if they don't first leave feeling more connected to and valued by the institution? How can it matter if students join an organization if they don't establish a sense of common purpose and community that meaningfully contributes to their learning and development at the institution? How can it matter if a student attends a leadership development initiative if they do not feel as if the initiative supports their goals or style of interacting in groups?

The impact of belonging is succinctly expressed in another seminal theory in student affairs, Tintos Theory of Departure (Tinto, 1993): "Other things being equal, the greater the contact among students, the more likely individuals are to establish social and intellectual membership in the social communities of the college and therefore the more likely they are to remain in college" (p. 118). In this way, belonging doesn't just improve students' experiences in college - it also leads to the completion of a degree.

\section{CRITICAL RACE THEORY - FUNDAMENTAL TO INCREASING STUDENT BELONGING}

Broadly speaking, Critical Race Theory (CRT) has received increased national attention in the media over the last few years primarily due to a lack of understanding of what it means to use an epistemological or methodological lens to critically examine racial issues in our society. During this same timeframe, we have seen a growth in the 
use of CRT as an epistemological lens for how scholars are examining strategies higher education can employ to create environments that serve the entire campus community (e.g., all students, faculty, and staff). The use of CRT to improve our higher education environment, specifically our students' experiences, is not new. In her 2016 article, Patton called for "more prominent scholarship on higher education grounded in CRT" (p. 316). Patton further noted that while "racism/White supremacy will not end," the academy "serves as a space for transformative knowledge production that challenges dominant discourses and ways of operating in and beyond the academy" (p. 335). While CRT has become embedded in higher education scholarship, CRT and how it can be applied to practice are less understood. CRT originated in critical legal studies (George, 2021) and, within its transition to the discipline of education (and specifically student affairs), does not possess a concrete definition. Rather, scholars understand that CRT provides a lens to "challenge conventional accounts of educational institutions... and the social processes that occur within them" (Powers, 2007, p. 151). CRT "cannot be confined to a static and narrow definition but is considered to be evolving and malleable" (George, 2021, para. 2).

It is important to note that CRT scholarship in higher education "help[s] to expose how race and racism are infused into the higher education culture" (Ledesma \& Calderón, 2015, p. 215). In that context, CRT does not provide the answer for improving our campus climates for belonging. Instead, it provides a lens to expose present inequities. It is important to note that CRT is a powerful tool for revealing the types of inequities that have been rendered invisible without a rigorous lens to examine them. Once exposed, campus activities professionals can alleviate them by working to create anti-racist environments.

Identifying strategies to address racial disparities in the work of campus activities offices requires an acknowledgment of the presence of racism within the environment. As critical values within the profession, DEI often represents topics frequently included in student leadership training programs. Campus activities professionals often work with students to consider these values as they plan broader campus events, suggesting policies whereby, for example, one campus lecture program must feature a focus on race, or a monthly bulletin board must feature stories of an underrepresented student population. Initiatives like these are essential in building a sense of belonging from students who have systemically been marginalized on most university campuses. However, alone, these are not enough.

The anti-racism movement has prompted numerous campuses to become more transparent in what they are specifically doing to address racism. As campus activities professionals continue to engage in the anti-racism movement, they need to examine how they are changing their organizational structures [e.g., budgets, policies, marketing strategies] and staff behaviors [e.g., mentoring, advising, leadership training approaches] to improve access to educational opportunities. For example, campus activities professionals might reflect on how frequently racial perspectives are shared in student organization training materials and specifically what students benefit from existing programs.

Reimagining the purpose of campus activities to "enhance the overall student educational experience through providing activities and events to facilitate students' sense of belonging and connection to the institution and the overall academic mission" (CAS, 2019, p.72) with a CRT and anti-racism lens will require a significant amount of time and attention. In examining what involvement and engagement practices are beneficial for historically underrepresented students, Kuh \& O'Donnell (2013) note that high-impact practices (HIPs) can be transformative and beneficial when done with attention to the qualities that make HIPs meaningful. As we consider the importance of student belonging within our work, we also need to recognize and listen to the experiences of racially minoritized students. Using CRT as a lens, Kinzie, Silberstein, McCormick, Gonyea, \& Dugan (2021) offer two points of consideration when structuring HIPs that center these practices "more squarely in racially minoritized students' lived experiences" (p. 13). Those HIP qualities are:

- Making a difference for others: Racially minoritized students value HIPs that emphasize opportunities to help others, make a difference, and encourage collaboration among students and between students and the larger community. HIPs could be better structured to allow students to maintain connections beyond the experience and to help students reflect on how they have made a difference.

- Agency and accomplishment: HIPs must be structured to empower minoritized students and provide opportunities for agency and achievement beyond simply enduring potentially unwelcome spaces. Similarly, biases and impediments to students' agency must be exposed and addressed. (p. 13). 
Campus activities professionals will need to think critically about what they learn about how racism is infused into our existing structures and take an active role in implementing anti-racist structures and behaviors to improve conditions for meaningful learning, involvement, and engagement. The new HIPs qualities provide a lens for how campus activities can create programming and spaces that encourage student belonging that acknowledge the voices of our diverse student populations.

\section{CONCLUSION}

Some may consider "DEI" a buzzword in higher education and within campus activities scholarship, but it cannot afford to be a fad. In this article, we have made a case that DEI initiatives are central to building student belonging and therefore central to the mission and purpose of the discipline of campus activities. When we plan events for the campus community, the purpose is to connect students with diverse others in meaningful ways. If our programs do not do that, they may simply replicate what would have happened naturally without our intervention. Indeed, college students, and humans in general, will gather with others like them and find a way to entertain themselves. Building a sense of student belonging among students who have been marginalized and connecting diverse students to each other and our institution is where campus activities professionals earn their salaries. Campus activities work provides students a valuable learning experience. If that learning experience does not include the chance to think about how to navigate cultural differences, confront inequitable and unjust systems, and foster a sense of inclusion within our teams and the people that they serve, then we are not preparing students for the diverse world in which they will live and work.

We hope that we have inspired campus activities professionals to challenge how we view our work. Moreover, we hope we have started a conversation that can continue in the forthcoming special issue of JCAPS that is specifically focused on diversity, equity, and inclusion in the context of campus activities scholarship and practice. We look forward to seeing how our readers and profession approach this critical conversation and make students feel valued by their institutions.

\section{REFERENCES}

Astin, A. W. (1984). Student involvement: A developmental theory for higher education. Journal of College Student Personnel, 25, 297-308.

Council for the Advancement of Standards in Higher Education. (2003). The book of professional standards for higher education. Washington, DC: Author.

Council for the Advancement of Standards in Higher Education. (2019). CAS professional standards for higher education (10th Ed.). Washington, DC: Author.

Dungy, G., \& Peck, A. (2019). How campus activities can lead the modern university: Five imperatives. Journal of Campus Activities Practice and Scholarship, 1(1), 6-13.

George, J. (2021, January 11). A lesson on critical race theory. The American Bar Association. https://www. americanbar.org/groups/crsj/publications/human_rights_magazine_home/civil-rights-reimaginingpolicing/a-lesson-on-critical-race-theory/

Hu, S. and Kuh, G.D. (2001) Being (dis)engaged in educationally purposeful activities: The influences of student and institutional characteristics. Paper presented at the American Educational Research Association Annual Conference. Seattle, WA, 10-14 April.

Johnson, L., \& Pierre, Y. (2021). Solving wicked diversity, equity, and inclusive problems from a design thinking lens. In Applying design thinking to the measurement of experiential learning. Information Science Reference, IGI Global. DOI:10.4018/978-1-7998-7768-4.ch004.

Kinzie, J., Silberstein, S., McCormick, A. C., Gonyea, R. M., \& Dugan, B. (2021). Centering racially minoritized student voices in high-impact practices. Change: The Magazine of Higher Learning, 53(4), 6-14. DOI: 10.1080/00091383.2021.1930976. 
Komives, S. R., Lucas, N., \& McMahon, T. R. (1998). Exploring leadership: For college students who want to make a difference. San Francisco: Jossey-Bass.

Kuh, G.D. (2007) How to help students achieve. Chronicle of Higher Education, 53(41), 12-13.

Kuh, G. D. (2008). High-impact educational practices: What they are, who has access to them, and why they matter. Washington, DC: Association of American Colleges and Universities.

Kuh, G. D., O’Donnell, K., \& Reed, S. (2014). Ensuring quality \& taking high-impact practices to scale. Peer Review, 16(2), 31-32.

Ledesma, M. C., \& Calderón, D. (2015). Critical race theory in education: A review of past literature and a look to the future. Qualitative Inquiry, 21(3), 206-222.

Patton, L. D. (2016). Disrupting postsecondary prose: Toward a critical race theory of higher education. Urban Education, 51(3), 315-342. DOI:10.1177/0042085915602542.

Peck, A., \& Callahan, K. (2019). Connecting student employment and leadership development. New Directions for Student Leadership, 162, 9-22. doi:10.1002/yd.20330.

Pfeffer, J. (2015). Leadership Bs: Fixing workplaces and careers one truth at a time. HarperCollins Publishers. DOI:10.1177/1742715017697514.

Powers, J. M. (2007). The relevance of critical race theory to educational theory and practice. Journal of Philosophy of Education, 41(1), 151-166. https://doi.org/10.1111/j.1467-9752.2007.00546.x.

Tinto, V. (1993). Leaving college: Rethinking the causes and cures of student attrition (2nd ed.). Chicago, IL: University of Chicago Press.

Whitt, E. J., Kuh, G. D., Schuh, J. H., Kinzie, J., \& Associates (2005). Student success in college. San Francisco: Jossey-Bass. 